\title{
Thermoresponsive laterally-branched polythiophene phenylene derivative as water-soluble temperature sensor
}

\author{
Eddie Wai Chi Chan, Paul Baek, Victor R. De la Rosa, David Barker, * Richard Hoogenboom \\ and Jadranka Travas-Sejdic*
}

Polymers with thermoresponsive properties have received a strong interest due to their potential applications. Here we report the synthesis and characterisation of a water soluble and thermoresponsive polythiophene derivative. Firstly, a polythiophene phenylene (PThP) functionalised with an initiator for atom transfer radical polymerization (ATRP) and azide groups on the side chains was synthesised. Secondly, ATRP was employed to graft poly(ethylene glycol) methacrylate (PEGMA) from the PThP to create a permanently water soluble conjugated polymer. Further functionalisation was then conducted through the 'click' reaction with propargyl functionalised poly(2-n-propyl-2oxazoline) to introduce thermoresponsivness. The polymer displayed lower critical solution temperature (LCST) behavior, as revealed by fluorescence and UV-Vis spectroscopy with potential use as soluble polymeric thermometer.

\section{Introduction}

Conjugated polymers have received great attention since their discovery and they are utilised for a wide range of applications such as biosensing, scaffolding, drug delivery systems and flexible electronics. ${ }^{1-6}$ For such applications, conjugated polymers with advanced functionalities are of interest and there is plenty of room for development of conjugated polymers with enhanced solubility, improved solid-state photoluminescence or equipped with biologically relevant moieties. ${ }^{7-13}$

We have previously reported the synthesis of the polythiophene phenylene (PThP) derivatives, ${ }^{14}$ which are highly functionalisable through side chains that are readily modified. This was achieved through the use of termonomers possessing functional side chains, allowing further post polymerisation modification. ${ }^{14} \mathrm{We}$ described the ability to incorporate simple molecules through 'click' chemistry as well as grafting of polymeric side chains using atom transfer radical polymerisation (ATRP) technique. ATRP has been studied extensively in various grafting systems, including "grafting from" conjugated polymer macroinitiators, by us and others. ${ }^{11,13,15-17}$

The interest in thermoresponsive polymers stems from their potential application across a wide variety of areas, including drug delivery, gene therapy, tissue engineering, biosensing, cell delivery, filtration systems and various other biomedical uses. ${ }^{18-26}$ The ability to change or adapt in a changing environment is the basis of many biological systems, thus there is strong interest in bestowing such smart or biomimetic properties to synthetic materials. ${ }^{18}$ An interesting example of thermoresponsive polymers are poly(2-alkyl-2oxazoline)s (PAOx). ${ }^{27}$ This class of polymer has received significant attention in recent years due to its biocompatibility, versatility and thermoresponsiveness with tuneable lower critical solution temperature (LCST) behaviour in water. ${ }^{28,29}$ Such behaviour is driven by the unfavourable entropy of bound water molecules in the hydration of the polymer, which above the cloud point temperature ( $\left.\mathrm{T}_{\mathrm{CP}}\right)$ becomes dominant, thereby leading to dehydration and insolubility of the polymer chains. ${ }^{18,24,30,31} \mathrm{The}_{\mathrm{CP}}$ is related to the ability of the polymer to form hydrogen bonds with water, which is dependent on the polymer structure and, therefore, can be tuned.

In this work, we developed thermoresponsive conjugated polymers with permanent aqueous solubility that can serve as temperature sensors. It was anticipated that the collapse of the thermoresponsive side-chains will induce a change in the local polarity and/or rotational freedom of the conjugated polymer leading to a change in optical properties that provide an output signal for the sensor. To reach this goal we envision to combine three polymer building blocks into the construct; namely, a conjugated polymer backbone with unique optical properties and two distinct side chains: poly(2-alkyl-2oxazoline) for thermoresponsiveness and a poly(poly(ethylene glycol)methacrylate) (PEGMA) for aqueous solubility. To this end, we have employed our previously developed functionalisable PThP derivative $^{14}$ as the conjugated polymer backbone, which is here utilised for grafting of PEGMA by means of ATRP, followed by grafting of propargyl functionalised poly(2n-propyl-2-oxazoline) (PnPropOx) by means of copper(I) catalysed azide-alkyne addition, better known as a 'click' reaction. ${ }^{32}$ The advantage of the PThP conjugated polymers is the ability to change the functionalised side chains appended to the central benzene ring of the termonomer, to introduce multiple orthogonal functionalities without interfering with either the polymerisation potential of the termonomer nor the planarity of the polymer. ${ }^{14}$ Here, we combined three different termonomers into a conjugated backbone; each termonomer comprises of either side chains with an ATRP radical initiator functional groups, azide groups or tri-ethylene glycol groups, where the latter was used as the 'inert spacers'. The resulting polymer combines, in a unique way, the optical properties of the polythiophene phenylene, temperature responsiveness and water solubility. 


\section{Experimental section}

Materials

Poly(ethylene glycol) methacrylate (PEGMA) ( $\mathrm{M}_{\mathrm{n}}$ 500), tin ethylhexanoate, anisole, copper(II) chloride, copper sulphate pentahydrate, ascorbic acid were acquired from Sigma Aldrich. All PThP was synthesised using the methodology developed by us previously. ${ }^{14}$ Propargyl functionalised PnPropOx was synthesised following the methodology developed by Fijten et al., ${ }^{33}$ using the more readily available propargyl benzenesulfonate as initiator. ${ }^{34}$ The characterisation data for the PnPropOx (4) are included in the ESI (Fig. S1-S3†). All other solvents and chemicals used in this work were analytical grade and used without further purification.

The conjugated polymer based macroinitiator used in this study, which possesses side chains containing triethylene glycol, azide and ATRP initiating sites (denoted PTTGThP, 1), was prepared using previously reported synthetic procedure. ${ }^{14}$
Synthesis

Grafting of PEGMA brushes via AGET ATRP. PEGMA $\left(\mathrm{M}_{\mathrm{n}} 500\right)$ brushes were grafted to the macroinitiator (1) via Activators Generated by Electron Transfer (AGET) ATRP in solution as shown in Scheme 1. PEGMA (2) (0.37 g,

$0.75 \mathrm{mmol}), 1(50 \mathrm{mg}), \mathrm{N}, \mathrm{N}, \mathrm{N}^{\prime}, \mathrm{N}^{\prime \prime}, \mathrm{N}^{\prime \prime}$-pentamethyldiethylenetriamine (4.20 $\mu \mathrm{L}, 0.020 \mathrm{mmol}), \mathrm{Cu}(\mathrm{II}) \mathrm{Cl}_{2}(1.5 \mathrm{mg}, 0.010 \mathrm{mmol})$, and anisole $(0.25 \mathrm{~mL})$ were dissolved in THF $(2.5 \mathrm{~mL})$, degassed by freeze-thawpump and placed in an atmosphere of $\mathrm{N}_{2}$. The solution was heated to $40{ }^{\circ} \mathrm{C}$ and a solution of ascorbic acid ( $\left.18 \mathrm{mg}, 0.10 \mathrm{mmol}\right)$ in $\mathrm{H}_{2} \mathrm{O}(0.50$ $\mathrm{mL}$ ) was added. The solution was stirred for $24 \mathrm{~h}$ and then quenched by exposure to air. The solvent was removed in vacuo, and the obtained crude polymer was redissolved in deionised $\mathrm{H}_{2} \mathrm{O}$ and purified by dialysis to obtain PThP-gPEGMA (3) (0.16 g).

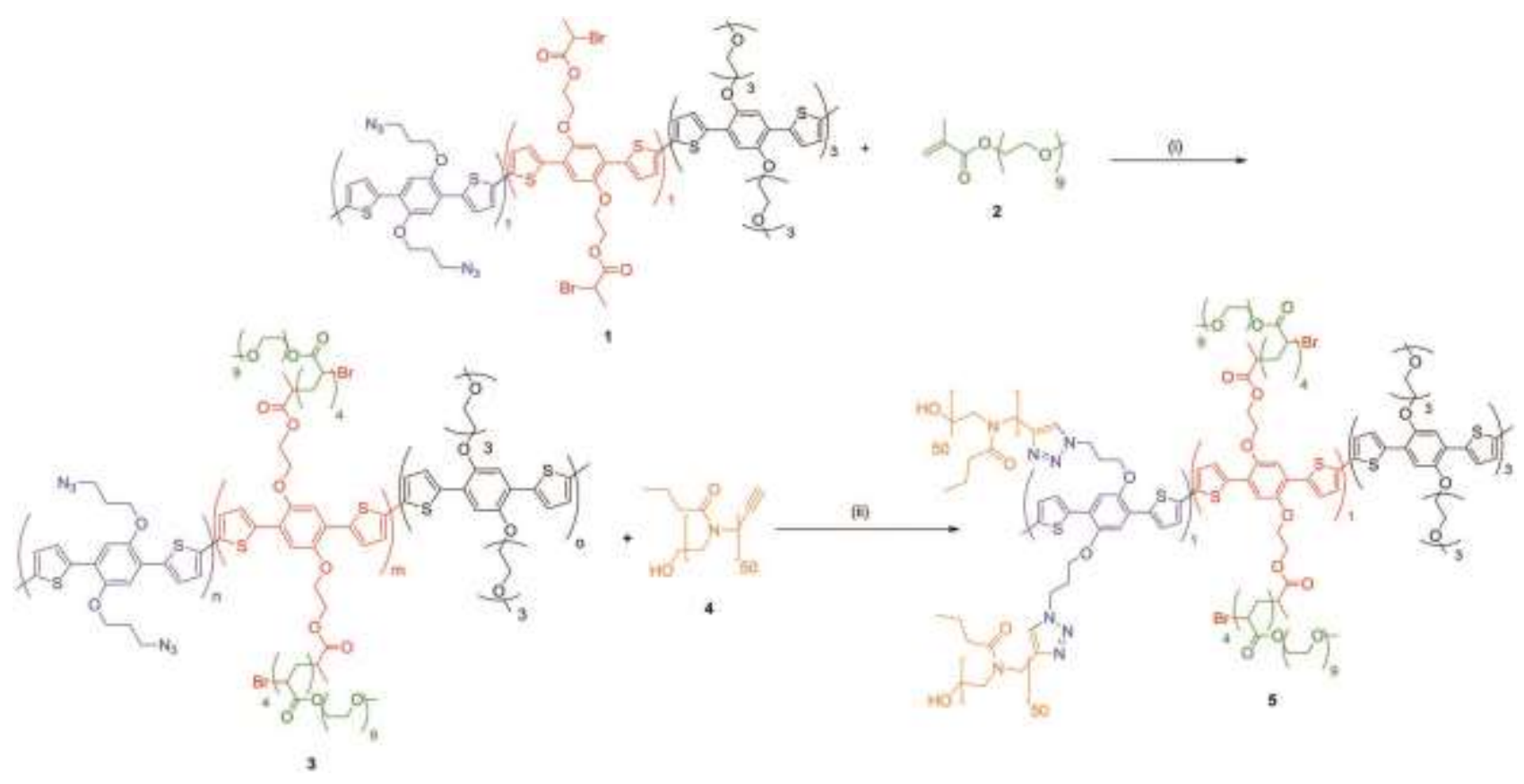

Scheme 1 ATRP grafting of PEGMA (2) to PThP to form PThP-g-PEGMA (3): (i) PMDETA, $\mathrm{Cu}(\Perp) \mathrm{Cl}_{2}$, ascorbic acid, anisole, $\mathrm{THF} \mathrm{H}_{2} \mathrm{O}, 40{ }^{\circ} \mathrm{C}, 24$; (ii) $\mathrm{Cu}(\Perp) \mathrm{SO}_{4} \cdot 5 \mathrm{H}_{2} \mathrm{O}$, ascorbic acid THF, $\mathrm{H}_{2} \mathrm{O}$, r.t., 24 h. 
Attachment of poly(2-n-propyl-2-oxazoline). PnPropOx (4) (0.20 g) and PThP-g-PEGMA (3) (80 mg) were dissolved in THF (2.5 mL). A solution of $\mathrm{Cu}(\mathrm{II}) \mathrm{SO}_{4} \cdot 5 \mathrm{H}_{2} \mathrm{O}(2.0 \mathrm{mg}, 8.0 \mu \mathrm{mol})$, ascorbic acid (1.4 $\mathrm{mg}, 8.0 \mu \mathrm{mol})$ in $\mathrm{H}_{2} \mathrm{O}(2.5 \mathrm{~mL})$ was added and the mixture was stirred at room temperature for $48 \mathrm{~h}$. Solvent was removed in vacuo. The crude polymer was then redissolved in $\mathrm{H}_{2} \mathrm{O}$ and purified by dialysis to obtain the fully functionalised conjugated PThP (f-PThP, 5) $(0.21 \mathrm{~g})$.

UV-Visible spectroscopy

UV-Visible spectroscopy was performed on a Shimadzu Spectrophotometer (Model UV-1700). For temperature measurements, a specialised temperature controller was used to heat or cool the cuvette. The temperature profile with a rate of $1{ }^{\circ} \mathrm{C} \mathrm{min}^{-1}$ was used. Polymer solutions with a concentration of $0.5 \mathrm{mg} \mathrm{mL}^{-1}$ were used for all temperature measurements.

Fluorescence spectroscopy

Fluorescence spectroscopy was performed on a PerkinElmer Fluorescence Spectrometer (Model LS55). For temperature measurements, a specialised temperature controller was used to heat or cool the cuvette. When the desired temperature was reached the sample was equilibrated for $1 \mathrm{~min}$ before the emission spectra was taken. Polymer solutions with a concentration of $0.5 \mathrm{mg} \mathrm{mL}^{-1}$ was used for all temperature measurements.

Quantum yield

Solution quantum yield was calculated according to the equation:

$$
\begin{array}{ccc}
\mathrm{I} & \mathrm{AR} & \mathrm{n} 2 \\
\Phi 1 / 4 \Phi_{\mathrm{R}} & \mathrm{TR}_{\mathrm{R}} & \mathrm{A}_{\mathrm{R} 2}
\end{array}
$$

where $\Phi$ is the quantum yield, I is the measured integrated emission intensity, $\mathrm{A}$ is the optical density, and $\mathrm{n}$ is the refractive index of the solvents used. The subscript $\mathrm{R}$ refers to the reference dye (fluorescein in ethanol: $\Phi=0.79$ ). For all polymer solutions, UV-Vis and fluorescence measurements were carried out using concentration of $0.5 \mathrm{mg} \mathrm{mL}^{-1}$.

Size exclusion chromatography

Molecular weights were determined with $\mathrm{TDA}_{\max }$ GPC system (Malvern Instruments) attached with $3 \times$ T6000M $(300 \mathrm{~mm} \times 8 \mathrm{~mm}$ each) Viscotech columns (Malvern Instruments). THF filtered through $0.02 \mu \mathrm{m}$ PTFE membrane filter (Grace) was used as eluent

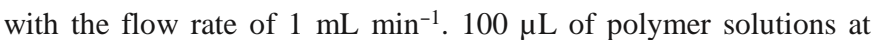
concentration of $3 \mathrm{mg} \mathrm{mL}^{-1}$ were injected into the column. All samples were filtered through $0.22 \mu \mathrm{m}$ PTFE syringe filters (Grace) before injection. The columns and the detectors were maintained at $35{ }^{\circ} \mathrm{C}$. Calibration curve was plotted using polystyrene standards obtained from Sigma. Data acquisition and processing were performed using the OmniSEC 4.7 software (Malvern Instruments). Triple point detection was used for calibration.
Determination of cloud point temperature

The cloud point measurements, which determine the LCST behaviour of the polymer in solution, were carried out by heating the functionalised conjugated polymers $\left(0.5 \mathrm{mg} \mathrm{mL}^{-1}\right)$ in $\mathrm{H}_{2} \mathrm{O}$ from various ranges of temperatures with a heating rate of $1{ }^{\circ} \mathrm{C} \mathrm{min}{ }^{-1}$. When the desired temperature was reached the sample was equilibrated for 1 min before the UV-Vis spectra was taken. Typically, the cloud point temperature $\left(\mathrm{T}_{\mathrm{CP}}\right)$ is reported as the temperature at which $50 \%$ transmittance is observed in UV-Vis spectroscopy. ${ }^{35}$

\section{Results and discussion}

Synthesis of water soluble, thermoresponsive PThP ( f-PThP)

Owing to their versatility in functionalisation, a PThP backbone was chosen for this study. The PThP backbone of interest consists of three termonomer building blocks, each with a different substituent: a triethylene glycol, an ATRP initiating site or an azide group (TTGThP, 1) (Scheme 1). The macroinitiator was prepared using a previously reported synthetic procedure. ${ }^{14}$ The PAOx used was propargylfunctionalised poly(2n-propyl-2-oxazoline), PnPropOx (4), which was prepared by living cationic ring-opening polymerisation of 2ethyl-2-oxazoline using propargyl benzenesulfonate as initiator, directly yielding the alkyne terminated polymer. ${ }^{33,34}$

Initially, the 'click' addition reaction of 1 with 4 was performed to produce the functionalised polymer PThP-c-PAOx. However, the resulting polymer was found to be insoluble in water, which limited its intended use as an aqueous sensor. It was then hypothesised that grafting of PEGMA side chains prior to the click reaction should afford water soluble PThPs. Grafting of PThP with PEGMA brushes was therefore performed first, followed by the click reaction. PEGMA brushes were successfully grafted using conditions optimised by us in a previous work for grafting from poly (3,4-ethylenedioxythiophene $)^{8}$ to yield the grafted copolymer PThP-g-PEGMA (3) (Scheme 1). The length of the grafts was estimated by comparing the molecular weights $\left(\mathrm{M}_{\mathrm{n}}\right)$ of 3 and the unfunctionalised PThP macroinitiator, 1 obtained from SEC measurements. $M_{n}$ of 1 was found to be approximately 8.05 $\times 10^{3} \mathrm{~g} \mathrm{~mol}^{-1}$ (Table S1 ${ }^{\dagger}$ ) whereas the grafted PThP 3 had a $\mathrm{M}_{\mathrm{n}}$ of 1.30 $\times 10^{4} \mathrm{~g} \mathrm{~mol}^{-1}$. This represents approximately 4 units of PEGMA was grafted on each initiating site; the chain length was sufficiently long to solubilise the final copolymer in water. Short grafted chains are also desirable to prevent the physical properties of the resulting polymer to be dominated by the characteristics of PEGMA and to allow more access to the azide-carrying sites on the conjugated backbone to allow for subsequent 'click' reaction. SEC trace of PThP-g-PEGMA (3) is presented in Fig. S4. ${ }^{+}$The polydispersity of PThP-g-PEGMA (3) is somewhat smaller than the macroinitiator which may be due to the grafted chains.

Following the successful grafting, of PEGMA chains, addition of PnPropOx (4) was performed through 'click' chemistry, using the reaction conditions we previously reported, ${ }^{14}$ by means of $\mathrm{CuSO}_{4} \cdot 5 \mathrm{H}_{2} \mathrm{O}$ and ascorbic acid as the catalyst system and THF/water 
mixture as the solvent system, to afford doubly-functionalised f-PThP (5) (with PEGMA and PAOx side chains).

The success of the reaction was determined using ${ }^{1} \mathrm{H}-{ }^{1} \mathrm{H}$ correlation spectroscopy (COSY) work. ${ }^{14}$ The chemical shifts of the crosspeaks for the propyl linker to the azide on PThP (1) (Fig. S5†) shifts after 'click' reaction (Fig. S6 $\left.{ }^{\dagger}\right)$. The clear amide peaks $(\sim 1680$ $\mathrm{cm}^{-1}$ ) in the FTIR spectra of the f-PThP (5) strongly indicated the presence of PAOx in the copolymer, PnProPOx (4) (Fig. S7†). The SEC trace (Fig. S ${ }^{+}$) shows one peak, which corresponds to molecular weight of $1.22 \times 10^{6} \mathrm{~g} \mathrm{~mol}^{-1}$ with PDI of 1.99 . However, it needs to be said that the SEC results are only indicative of the actual molecular weights due to the complexity of the polymer structures relative the PS standards used. The ${ }^{1} \mathrm{H}$ NMR of the polymers synthesised are presented in Fig. S9-S11. ${ }^{+}$

The observed $\mathrm{T}_{\mathrm{CP}}$ for PnPropOx (4) was $32^{\circ} \mathrm{C}$ (Fig. 1A), whereas the f-PThP's cloud point was shifted to somewhat higher temperature of $37{ }^{\circ} \mathrm{C}$. The $\mathrm{T}_{\mathrm{CP}}$ for PEGMA homopolymers was as previously
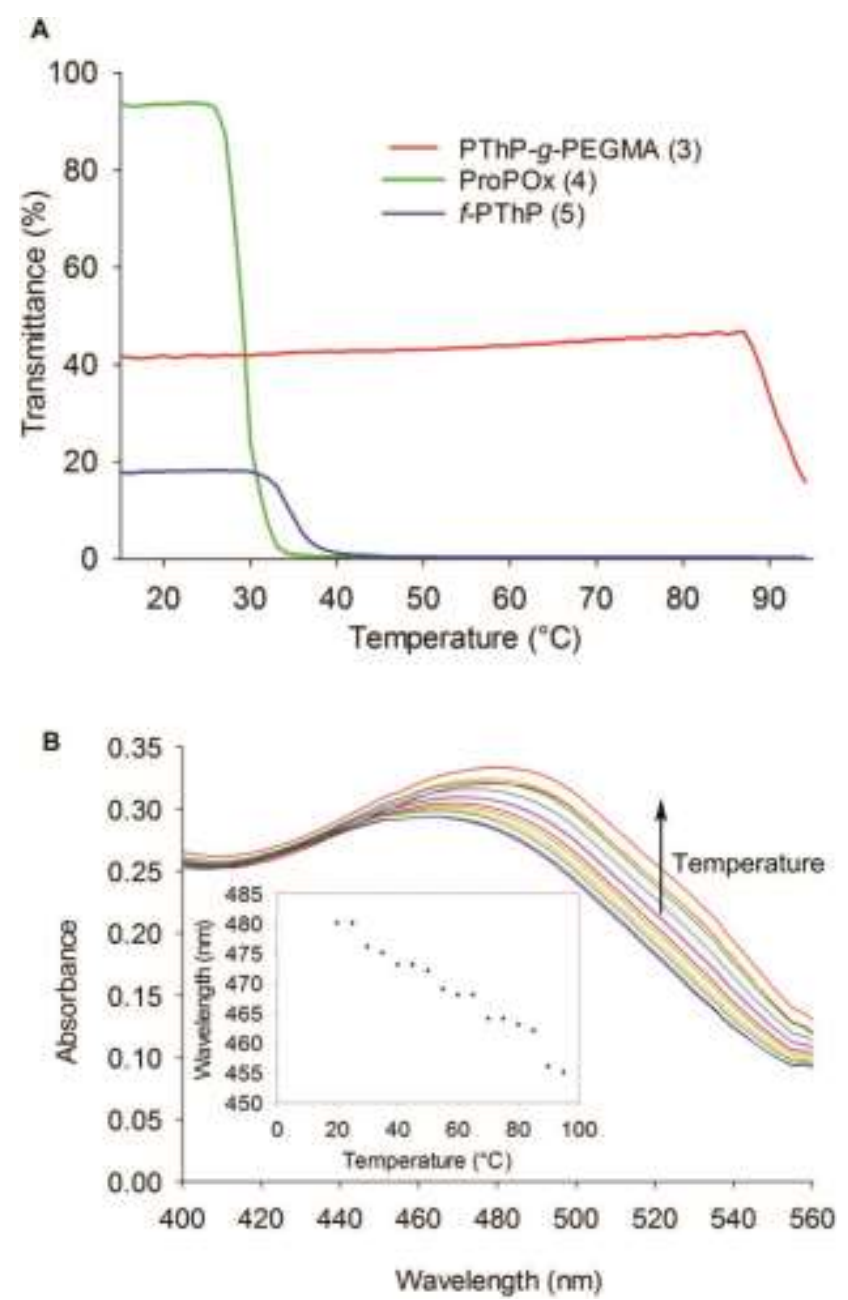

Fig. 1 (A) Temperature dependent transmittance at specified wavelengths for PThPg-PEGMA (3) (463 nm), PnPropOx (4) (450 nm) and fPThP (5) (468 nm), (B) temperature dependent UV-Vis for PThP-gPEGMA (3). Inset: Maximum absorption wavelength versus temperature. published at $90{ }^{\circ} \mathrm{C} .{ }^{36,37}$ There is a decrease in absorbance and blue shift in wavelength for PThPg-PEGMA (3) in the temperature range from $20{ }^{\circ} \mathrm{C}$ to $95{ }^{\circ} \mathrm{C}$ as seen in Fig. $1 \mathrm{~B}$, where the wavelength of the maximum absorption shifted from $480 \mathrm{~nm}$ at $25^{\circ} \mathrm{C}$ to $455 \mathrm{~nm}$ at 80 ${ }^{\circ} \mathrm{C}$. The shift to shorter wavelengths for polythiophene derivatives under heating had previously been reported by Kang et al. ${ }^{38}$ This can be explained by looking at the core structure of PThP; the deplanarization of the aromatic rings decreases the delocalisation of $\pi$-electrons. ${ }^{39}$ There are free rotations of the aromatic rings of PThP and the rotational rate increases at warmer temperatures leading to a decrease of conjugation. ${ }^{40}$

The cloud point measurements performed by means of turbidimetry, pointed to differences in the phase behaviour of PThPg-PEGMA (3), PnPropOx (4), and f-PThP (5) (Fig. 1A). As the PThPg-PEGMA (3) is photoluminescent, and the f-PThP (5) undergoes LCST with $\mathrm{T}_{\mathrm{CP}}$ of $37{ }^{\circ} \mathrm{C}$ as observed by UV-Vis, we postulated that the photoluminescence of the $\mathrm{f}-\mathrm{PThP}$ (5)

would be temperature dependent. Therefore, the photoluminescence of PThP-g-PEGMA (3) and f-PThP (5) in the temperature range of 27 to $65{ }^{\circ} \mathrm{C}$ was investigated. For PThP-gPEGMA (3), a slight decrease in photoluminescence (PL) emission intensity was observed between $27{ }^{\circ} \mathrm{C}$ and $65{ }^{\circ} \mathrm{C}$ (Fig. 2A). Such decrease in PL corresponds to the observed decrease in $\mathrm{UV}-\mathrm{V}$ is intensity in the same temperature range $\left(40-80{ }^{\circ} \mathrm{C}\right)$

(Fig. 1A).

Thermoresponsive f-PThP (5) demonstrated very different behaviour (Fig. 2B). At temperature beyond $30{ }^{\circ} \mathrm{C}$, there is an increase in photoluminescence intensity with a sharp increase observed between $33{ }^{\circ} \mathrm{C}$ and $36{ }^{\circ} \mathrm{C}$; that temperature range corresponds well with the $T_{C P}$ value of $f-P T h P(5)$ (Fig. 2A). The optical images of an $f-$ PThP (5) solution confirm there is clouding (Fig. 2C). The solution however continues to become lighter in colouration up to $60{ }^{\circ} \mathrm{C}$, this corresponds to the increase of PL beyond the $\mathrm{T}_{\mathrm{CP}}$ and up till $60^{\circ} \mathrm{C}$

An increase in PL intensity of $\mathrm{f}-\mathrm{PThP}(5)$ as the temperature increases beyond $\mathrm{T}_{\mathrm{CP}}$ of PnPropOx (4) (and f-PThP (5)) was observed. As seen from UV-Vis measurements, the PAOx component of the polymer clearly undergoes a LCST phase transition in the temperature range between $33{ }^{\circ} \mathrm{C}$ and $45^{\circ} \mathrm{C}$. The optical images in the Fig. $2 \mathrm{C}$ suggest that there is an onset of clouding observed for f-PThP (5) at ca. $40 \mathrm{C}$. The increased PL intensity as the temperature is raised up to ca. $60{ }^{\circ} \mathrm{C}$, indicates that the collapse of PAOx chains forces the PThP backbone into a more extended conformation leading to an increase in the extent of conjugation and therefore increased PL intensity, as depicted in Fig. 3. The increase in PL intensity due to attachment of polymeric chains had previously been reported by us, which was suggested to be due to prevention of backbone aggregation and decrease in self-quenching. ${ }^{41,42}$

From $65{ }^{\circ} \mathrm{C}$ to $80{ }^{\circ} \mathrm{C}$ there is a levelling off in PL intensity (Fig. 2B). We also observe that there is no shift in the PL emission peak wavelength with variation in the temperature suggesting that $f-P T h P$ (5) is not aggregating. ${ }^{43,44} \mathrm{We}$ propose that at temperatures beyond 60 ${ }^{\circ} \mathrm{C}$, the free rotational energy 
$\mathrm{Fi}$

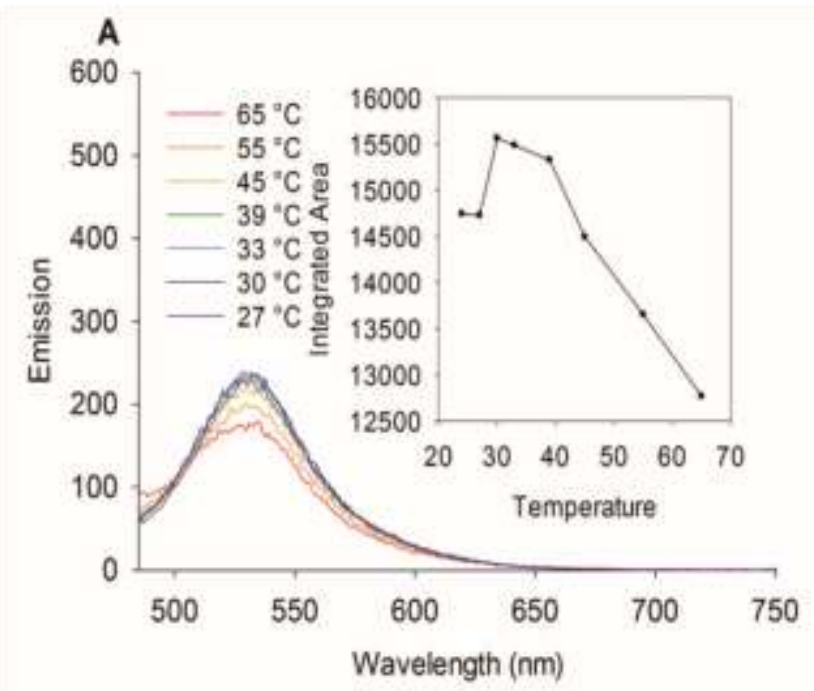

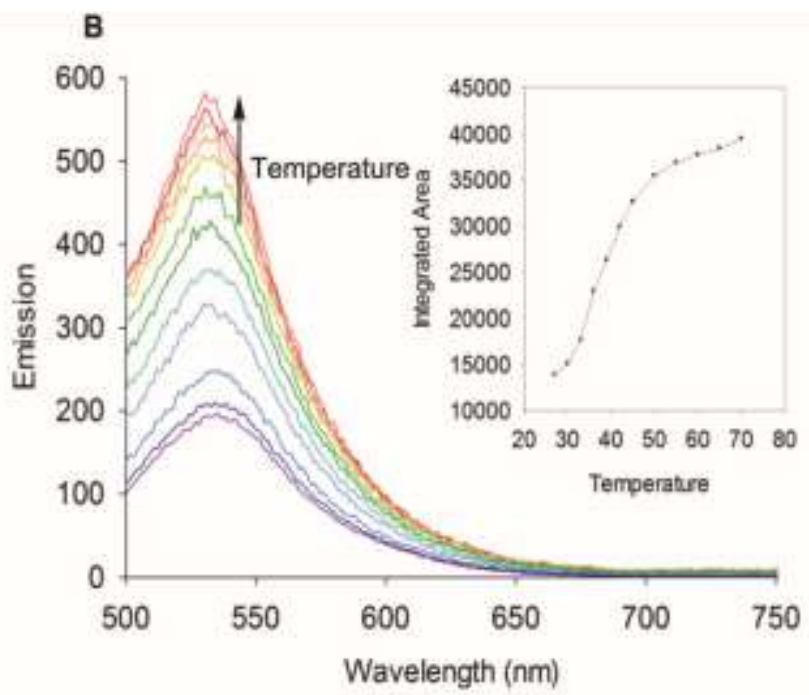

C

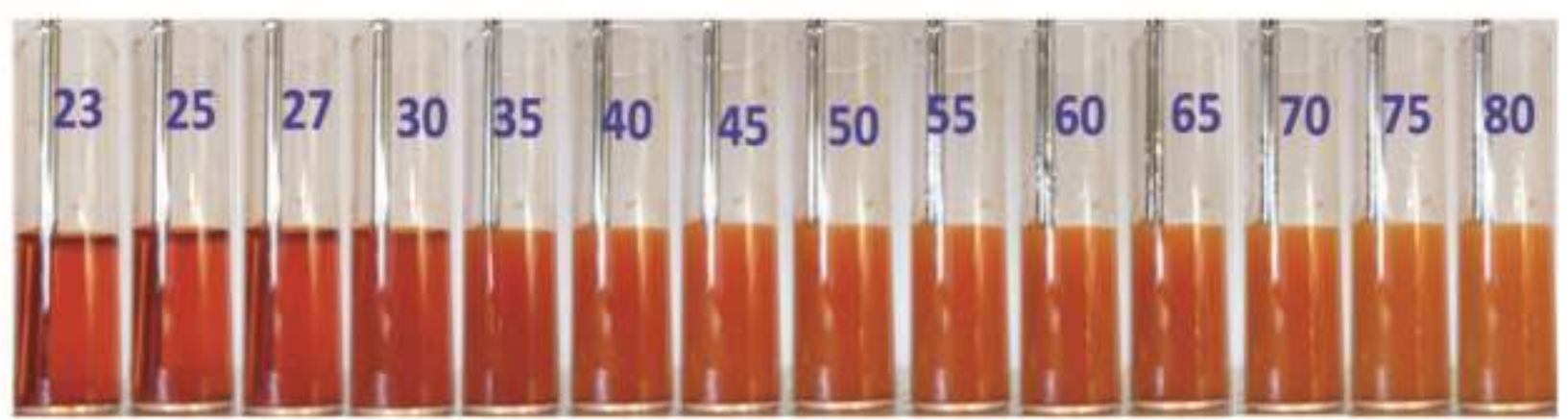

(B) temperature dependent fluorescence of f-PThP (5) excited at $476 \mathrm{~nm}$. Inset: Integrated fluorescence emission peak area vs. temperature, (C) images of f-PThP (5) in $\mathrm{H}_{2} \mathrm{O}\left(5 \mathrm{mg} \mathrm{mL}^{-1}\right)$ at different temperatures.

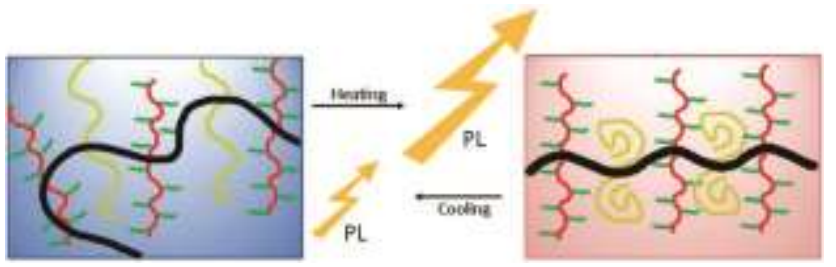

Fig. 3 Suggested mechanism for increase of PL for f-PThP (5).

both PAOx chains (gold) and PEGMA (red and green) chains are extended. At heating past $37^{\circ} \mathrm{C}$ (right), PAOx chains are collapsed while the PEGMA chains are still extended.
DMF) and water were investigated. The QY for PThP-g-PEGMA (3) were higher than f-PThP (5) for both organic solvents and water; the difference in QY between 3 and 5 was stipulated to be due to reduced solubility of 5 due to the attachment of a large polymeric side chain on f-PThP (5). The QY of f-PThP (5) had shown changes in response to temperature, with a drop in QY value between $35^{\circ} \mathrm{C}$ and $40{ }^{\circ} \mathrm{C}$ from 0.028 to 0.019 ; this is also the temperature range of the cloud point. There were no significant changes in QY in response to temperature for PThP-g-PEGMA (3). 
between the rings of f-PThP (5) backbone, as discussed above, begins to usurp the planarity-inducing effect of the coiled PAOx and thus observed levelling in PL. From the above, clearly, both PEGMA and PAOx side chains on the PThP backbone contribute to the thermoresponsive behaviour of the f-PThP (5).

The quantum yield (QY) (Table S2 + ) for PThP-g-PEGMA (3) and f-PThP (5) in both organic solvents (chloroform, THF and

\section{Conclusions}

We have demonstrated the synthesis of a polythiophene phenylene (PThP) functionalised with both an initiator for ATRP and azide groups, where ATRP was employed to graft poly(ethylene glycol)methacrylate (PEGMA) on the side chains and azide groups to 'click' propargyl functionalised poly(2-n-propyl2-oxazoline). The former provides water solubility to the final polymer and the later introduces thermoresponsiveness. The final polymer displayed lower critical solution temperature (LCST) behaviour. The three distinct components of the final polymer, PThP, PAOx and grafted PEGMA brushes, all had aspects of their physical properties present in the final compound; the fluorescence and UV activity from the conjugated PThP backbone, the enhanced water solubility from PEGMA chains and the temperature responsiveness from poly(2-oxazoline). This work illustrates a great potential of functionalization of multifunctional PThP and demonstrates that 'click' cycloaddition of large side chains, such PAOx, is possible even onto the PThP polymer that already carries a relatively long PEGMA chains. This finding opens up a range of opportunities in functionalisation of conjugated polymers.

\section{Acknowledgements}

This work was supported by grant from the Ministry of Business, Innovation and Employment, New Zealand (91463701426). VR acknowledges the Agency for Innovation by Science and Technology of Flanders (IWT). RH is grateful to BELSPO (IAP VII/5 Functional Supramolecular Systems FS2), FWO and UGent (BOF) for financial support. The authors thank Assoc. Prof. S. Moratti from the University of Otago, New Zealand, for the help with performing GPC measurements.

\section{Notes and references}

1 D. Svirskis, J. Travas-Sejdic, A. Rodgers and S. Garg, J. Controlled Release, 2010, 146(1), 6-15. 2 A.-D. Bendrea, L. Cianga and I. Cianga, J. Biomater. Appl., 2011, 26(1), 3-84.

3 M. J. Higgins, P. J. Molino, Z. Yue and G. G. Wallace, Chem. Mater., 2012, 24(5), 828-839.

4 G. G. Wallace, S. E. Moulton and G. M. Clark, Science, 2009, 324(5924), 185-186.

5 G. Gustafsson, Y. Cao, G. M. Treacy, F. Klavetter, N. Colaneri and A. J. Heeger, Nature, 1992, 357(6378), 477-479.

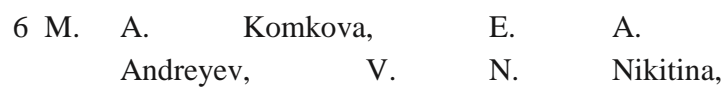
V. A. Krupenin, D. E. Presnov, E. E. Karyakina, A. K. Yatsimirsky and A. A. Karyakin, Electroanalysis, 2015, 27(9), 2055-2062.

7 R. D. McCullough and S. P. Williams, J. Am. Chem. Soc., 1993, 115(24), 11608-11609.

8 A. J. Hackett, J. Malmström, P. J. Molino, J. E. Gautrot, H. Zhang, M. J. Higgins, G. G. Wallace, D. E. Williams and J. Travas-Sejdic, J. Mater. Chem. B, 2015, 3(48), 9285- 9294.

9 T. E. Kerr-Phillips, V. Woehling, R. Agniel, G. T. M. Nguyen, F. Vidal, P. Kilmartin, C. Plesse and J. Travas-Sejdic,

J. Mater. Chem. B, 2015, 3(20), 4249-4258. 10 Y. Pei, J. TravasSedjic and D. E. Williams, Langmuir, 2012, 28(37), 13241-13248.

11 L. Strover, C. Roux, J. Malmström, Y. Pei, D. E. Williams and J. Travas-Sejdic, Synth. Met., 2012, 162(3-4), 381-390.

12 N. Aydemir, J. Parcell, C. Laslau, M. Nieuwoudt, D. E. Williams and J. Travas-Sejdic, Macromol. Rapid Commun., 2013, 34(16), 1296-1300.

13 L. T. Strover, J. Malmström, O. Laita, J. Reynisson, N. Aydemir, M. K. Nieuwoudt, D. E. Williams, P. R. Dunbar, M. A. Brimble and J. Travas-Sejdic, Polymer, 2013, 54(4), 1305-1317. 14 E. W. C. Chan, P. Baek, D. Barker and J. Travas-Sejdic, Polym. Chem., 2015, 6(43), 7618-7629. 15 K. Matyjaszewski, S. Gaynor, D. Greszta, D. Mardare and T. Shigemoto, J. Phys. Org. Chem., 1995, 8(4), 306-315. 16 K. Matyjaszewski, H. Dong, W. Jakubowski, J. Pietrasik and A. Kusumo, Langmuir, 2007, 23(8), 4528-4531.

17 J. Malmström, M. K. Nieuwoudt, L. T. Strover, A. Hackett, O. Laita, M. A. Brimble, D. E. Williams and J. Travas-Sejdic, Macromolecules, 2013, 46(12), 4955-4965. 18 D. Roy, W. L. A. Brooks and B. S. Sumerlin, Chem. Soc. Rev., 2013, 42(17), 72147243.

19 M. C. Hacker, L. Klouda, B. B. Ma, J. D. Kretlow and

A. G. Mikos, Biomacromolecules, 2008, 9(6), 1558-1570. 20

J.-F. Lutz, Adv. Mater., 2011, 23(19), 2237-2243.

21 C. Bradley, N. Jalili, S. K. Nett, L. Chu, R. Förch, J. S. Gutmann and R. Berger, Macromol. Chem. Phys., 2009, 210(16), 13391345.

22 L. Hu, L.-Y. Chu, M. Yang, J. Yu and H.-D. Wang, Chem. Eng. Technol., 2007, 30(4), 523-529.

23 A. M. Jonas, Z. Hu, K. Glinel and W. T. S. Huck, Nano Lett., 2008, 8(11), 3819-3824.

24 D. m. Jones, J. r. Smith, W. t. s. Huck and C. Alexander, Adv. Mater., 2002, 14(16), 1130-1134.

25 F. Zhou, W. Shu, M. E. Welland and W. T. S. Huck, J. Am. Chem. Soc., 2006, 128(16), 5326-5327.

26 J. P. A. Custers, S. F. G. M. van Nispen, A. Can, V. R. de La Rosa, S. Maji, U. S. Schubert, J. T. F. Keurentjes and R. Hoogenboom, Angew. Chem., Int. Ed., 2015, 54(47), 14085-14089.

27 R. Hoogenboom and H. Schlaad, Polym. Chem., 2017, 8, 24-40. 
28 N. Adams and U. S. Schubert, Adv. Drug Delivery Rev., 2007, 59(15), 1504-1520.

29 R. Luxenhofer, Y. Han, A. Schulz, J. Tong, Z. He, A. V. Kabanov and R. Jordan, Macromol. Rapid Commun., 2012, 33(19), 16131631.

30 M. A. Boerman, H. L. Van der Laan, J. C. M. E. Bender, R. Hoogenboom, J. A. Jansen, S. C. Leeuwenburgh and J. C. M. Van Hest, J. Polym. Sci., Part A: Polym. Chem., 2015, 15731582.

31 R. Hoogenboom, Angew. Chem., Int. Ed., 2009, 48(43), 79787994.

32 H. C. Kolb, M. G. Finn and K. B. Sharpless, Angew. Chem., Int. Ed., 2001, 40(11), 2004-2021.

33 M. W. M. Fijten, C. Haensch, B. M. van Lankvelt, R. Hoogenboom and U. S. Schubert, Macromol. Chem.

Phys., 2008, 209(18), 1887-1895.

34 E. D. H. Mansfield, V. R. de la Rosa, R. M. Kowalczyk, I. Grillo, R. Hoogenboom, K. Sillence, P. Hole, A. C. Williams and V. V. Khutoryanskiy, Biomater. Sci., 2016, 4(9), 1318-1327.

35 C. Boutris, E. G. Chatzi and C. Kiparissides, Polymer, 1997, 38(10), 2567-2570.

36 M. Mertoglu, S. Garnier, A. Laschewsky, K. Skrabania and J. Storsberg, Polymer, 2005, 46(18), 7726-7740. 37 J.-F. Lutz and A. Hoth, Macromolecules, 2006, 39(2), 893-896.

38 T. J. Kang, J. Y. Kim, K. J. Kim, C. Lee and S. B. Rhee, Synth. Met., 1995, 69(1-3), 377-378.

39 M. Levitus, K. Schmieder, H. Ricks, K. D. Shimizu, U. H. F. Bunz and M. A. Garcia-Garibay, J. Am. Chem. Soc., 2001, 123(18), 4259-4265.

40 R. Traiphol, P. Sanguansat, T. Srikhirin, T. Kerdcharoen and T. Osotchan, Macromolecules, 2006, 39(3), 1165-1172.

41 P. Baek, T. Kerr-Phillips, M. Damavandi, O. J. Chaudhary, J. Malmstrom, E. W. C. Chan, P. Shaw, P. Burn, D. Barker and J. Travas-Sejdic, Eur. Polym. J., 2016, 84, 355-365. 42 P. J. Costanzo and K. K. Stokes, Macromolecules, 2002, 35(18), 68046810 .

43 T.-Q. Nguyen, V. Doan and B. J. Schwartz, J. Chem. Phys., 1999, 110(8), 4068-4078.

44 B. S. Gaylord, S. Wang, A. J. Heeger and G. C. Bazan, J. Am. Chem. Soc., 2001, 123(26), 6417-6418. 